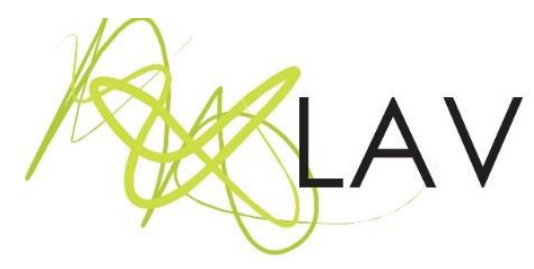

\title{
Confluencias entre la educación artística y las tecnologías de la imagen
}

\author{
Confluências entre a educação artística e as tecnologias da imagem
}

Confluences between art education and image technologies

\author{
Gonzalo Vicci Gianottiii \\ Universidad de la República, Uruguay
}

\begin{abstract}
Resumen
En nuestra contemporaneidad, la fotografía y a las imágenes presentan un amplio espacio de posibilidades de trabajo en torno a la educación artística. Cotidianamente nos enfrentamos a una sucesión de recursos y dispositivos tecnológicos que podemos utilizar como herramientas, que contienen implícitamente disparadores que nos permiten plantear discusiones y reflexiones en cuanto a su utilización como estrategias educativas, obligando a replantear incluso los alcances de las imágenes y su relación con los individuos. Nen este texto se proponen algunos abordajes que nos permiten pensar en la relevancia que revisten las imágenes - en particular las fotografías - en la construcción de imaginarios personales y colectivos. Se propone reflexionar en torno a la forma en que se han reformulado las concepciones que, en relación a la imagen fotográfica, se manejaron desde la segunda mitad del siglo XX y la manera en que la fotografía - desde su invención - ha transitado por diversos cambios tecnológicos que han impactado y reorientado su utilización e impacto en el uso cotidiano y profesional.
\end{abstract}

Palabras clave: fotografía, educación, cultural visual.

\begin{abstract}
In contemporaneity, photography and images present a wide space of possibilities for working around artistic education. Everyday we face a succession of resources and technological devices that we can use as tools, implicitly containing triggers that allow us to raise discussions and reflections regarding their use as educational strategies, forcing us to rethink even the scope of the images and their relationship with the individuals. In this text, we propose some approaches that allow us to think about the relevance of images - particularly photographs - in the construction of personal and collective imaginaries. It is proposed to reflect on the way in which the conceptions that, in relation to the photographic image, were handled since the second half of the 20th century have been reformulated and the way in which photography - since its invention - has undergone various technological changes, which have impacted and reoriented their use and impact on daily and professional use.
\end{abstract}

Keywords: fotografía, educación, cultural visual. 
"Lo que la Fotografía reproduce al infinito únicamente ha tenido lugar una sola vez; la Fotografía repite mecánicamente lo que nunca más podrá repetirse existencialmente.

En ella el acontecimiento no se sobrepasa jamás para acceder a otra cosa. La Fotografía remite siempre el corpus que necesito, al cuerpo que veo..." (BARTHES, 2009).

Cuando hablamos de posibilidades de trabajo en torno a la educación artística resulta imposible no referirnos a la fotografía y a las imágenes como componentes esenciales para cualquier abordaje que nos propongamos. Nuestra contemporaneidad nos plantea una sucesión de recursos y dispositivos tecnológicos que podemos utilizar como herramientas, que contienen implícitamente disparadores que nos permiten plantear discusiones y reflexiones en cuanto a su utilización como estrategias educativas, obligando a replantear incluso los alcances de las imágenes y su relación con los individuos.

Es necesario pensar en la relevancia que revisten las imágenes -en particular las fotografías- en la construcción de imaginarios personales y colectivos. Notoriamente el desarrollo tecnológico de la última década, ha reformulado las concepciones que, en relación a la imagen fotográfica, se manejaron desde la segunda mitad del siglo XX. La fotografía desde su invención ha transitado por diversos cambios tecnológicos que han impactado y reorientado su utilización e impacto en el uso cotidiano y profesional.

Al mismo tiempo, la necesidad de nuestra época por "registrar" o "conservar" a través de las imágenes los momentos y acontecimientos vividos, ha generado diversos mecanismos para su conservación, catalogación y difusión. Todo esto conjugado con un desarrollo tecnológico de las cámaras fotográficas y telefonía celular que multiplican exponencialmente su definición y posibilidad de utilización, al mismo tiempo que se produce el desarrollo de internet y herramientas de comunicación que se sustentan en la imagen como su razón de ser.

Pensemos en Facebook como paradigma de esta nueva situación, que se plantea a esta altura como un hecho natural, pero que transforma claramente nuestra relación con las imágenes propias y las de los demás. Es decir, las fotografías hoy, en tanto que no sólo 
pertenecen al campo de lo artístico, profesional, apartado de lo doméstico. Por el contrario, las imágenes impregnan nuestra realidad cotidiana y nos construyen en relación a los otros. Imágenes/fotografías en la calle, en la escuela, en el trabajo, en un álbum familiar, en las redes sociales, en la publicidad, en los libros de estudio, en los alimentos que ingerimos; todas esas imágenes son discursos que remiten a una intencionalidad, técnica y política o ideológica.

Claro está que las imágenes que yo selecciono para mostrarme (ante los otros) es también un texto escrito para alguien, constituye un discurso que yo elaboro sobre mí, en relación al otro, a las imágenes que el otro decide mostrarme sobre él. Y también debemos tener en cuenta que las imágenes que consumimos a diario, aportan a la construcción de realidades que de alguna u otra forma constituyen un discurso sobre algo de los que nos rodea, que podrá estar más cerca o más lejos, pero que siempre contribuye a edificar otras imágenes en relación a nosotros y a los otros.

La fotografía mantiene entonces las posibilidades que la tecnología brinda para la construcción de realidades ya sea desde el desarrollo de la destreza técnica, profesional, como disciplina específica del campo artístico, así como de lo cotidiano, político e ideológico en el más amplio campo de producción y circulación.

Desde las primeras fotografías de Niépce ${ }^{1}$ donde aparecían los tejados de Grás, hasta la fotografía tomada en 2012 donde aparece Barack Obama y su equipo de gobierno en la Casa Blanca -en momentos en que Bin Laden era capturado- muestran la permanente amplitud, diversidad y posibilidades que la toma fotográfica puede otorgar para quien quiera generar un discurso, construir una verdad, recortarla, inventarla, hacerla circular y generar otras miradas sucesivas y superpuestas.

La cuestión sobre la verdad en la fotografía, sobre su capacidad de mostrarnos algo tal como sucedió, de adjudicarle ese valor de "verdad" sólo por el hecho de haber sido capturado a través de un dispositivo tecnológico que estaba en el lugar y en el momento exacto cuando sucedía el acontecimiento, también nos plantea el desafío de cuestionar si siempre es así.

\footnotetext{
${ }^{1}$ Se puede encontrar más información acerca de la la obra de Joseph Nicéphore Niépce y la historia de la fotografía en el sitio: http://www.photography-museums.com/
} 


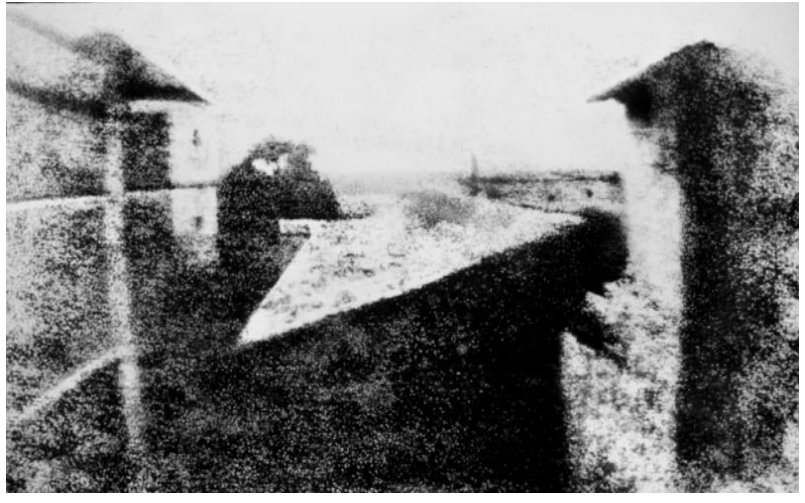

Figura 01. Nicéphore Niépce (1826 - 1827).

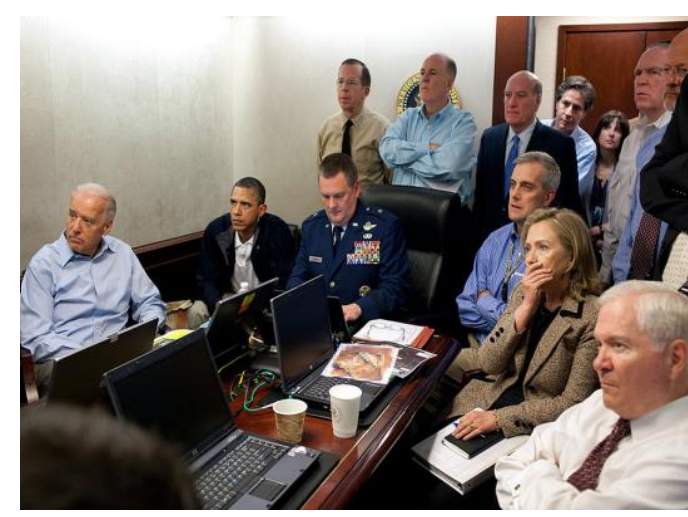

Figura 02. Pete Souza (Casa Blanca).

Vista desde la ventana en Le Gras.

Durante el siglo XX este carácter inherente al lenguaje fotográfico fue cuestionado y en algunos casos derribado.

Como sostenía Susan Sontag (1977, p.184):

La fotografía no se limita a reproducir lo real, lo recicla: un procedimiento clave de la sociedad moderna. En forma de imágenes fotográficas, las cosas y los acontecimientos son sometidos a usos nuevos, reciben nuevos significados que trascienden las distinciones entre lo bello y lo feo, lo verdadero y lo falso, lo útil y lo inútil, el buen gusto y el mal gusto. La fotografía es uno de los principales medios para producir esa cualidad que borra dichas distinciones cuando se la adjudica a las cosas "lo interesante".

Hoy, cuando nos enfrentamos a las imágenes, no podemos menos que dudar acerca de lo que esas imágenes nos dicen y al mismo tiempo ponerlas a dialogar con lo que dicen de nosotros. Es decir: ¿desde dónde nos paramos para poder dialogar con ellas?, ¿Cuáles son los conceptos, ideas, prejuicios que manejamos en relación a lo que nos muestran? ¿Que buscamos ver? ¿Qué proponernos que vean de nosotros?

Hoy todos generamos imágenes, en diversas situaciones, cotidianamente y las hacemos circular por diferentes medios. Permanentemente estamos generando discursos y nuevas miradas sobre nuestras realidades, nuestros amigos y familiares, nuestro entorno. Elegimos a quien mostramos esas imágenes y de qué manera queremos que nos miren. Al mismo tiempo nuestras fotografías circulan sin que tengamos claro quien las ve y como. Ese juego, paradójico, implica creer que estamos controlando nuestras imágenes cuando en realidad siempre hay imágenes nuestras que no podemos controlar. Aquí aparecen 
entonces aspectos relacionados con nuestras subjetividades, con nuestra intimidad y de qué forma es moldeada por esos discursos que negociamos a diario.

Seguramente todos tenemos una colección de fotografías. En diferentes formatos -en papel, en un notebook o en nuestro teléfono celular-, de un viaje, de un cumpleaños, de una fiesta, de cuando éramos pequeños, de nuestros familiares, de nuestros antepasados, de nuestros hijos, de nuestra clase en la escuela primaria, etc.

Esas colecciones, de alguna manera, son escritos sobre nuestra historia. Esas imágenes han construido discursos sobre nosotros, discursos que manejamos explícita o implícitamente pero que generan miradas acerca de momentos que pasaron, que pertenecen a un tiempo que ya no está.

Esas "realidades" que están contenidas en la imagen remiten inevitablemente a un hecho de carácter efímero. Más allá de compartir y subrayar el este carácter inherente a la herramienta, en cuanto a la captura de ese instante, al momento de fotografiar un acontecimiento, implícitamente estamos frente a algo que tiene carácter efímero (incluso si pensamos en un edificio o lugar físico). La fotografía, entonces, nunca estará despojada de la complejidad de analizar una serie de factores que remiten a la condición documental como ser las condiciones en fue realizada la imagen, el sujeto, el momento histórico, quién toma la fotografía o porqué motivo.

Cuando nos posicionamos frente a las imágenes, participamos en una especie de juego que aceptamos tácitamente, donde a la supuesta "autonomía del objeto/imagen", se agrega el imaginario del sujeto/espectador que elabora y re-elabora significado y visualidad, generando nuevas imágenes a través de su respuesta o adjudicando deliberada intencionalidad en la imagen a la que nos enfrentamos.

Cada imagen representa la memoria de un momento único, cuyo contenido, alguien (un fotógrafo o un amateur) no quiso olvidar y lo retuvo comprimido en un espacio. Esas imágenes fueron adquiriendo con el tiempo un valor que ya no es propio solamente de la imagen sino del objeto completo. Una fotografía, por ejemplo, del siglo XIX, es hoy un objeto de colección, un todo completo, con su soporte, las inscripciones del fotógrafo, las firmas, los envoltorios, las dedicatorias de los retratados, etc. Son todos elementos que la constituyen en un bello objeto, un valioso legado de nuestro pasado que se ha transformado hoy, además, en una importante fuente histórica. 
Toda y cualquier fotografía, además de ser un residuo del pasado, es también un testimonio visual donde se pueden detectar -tal como ocurre con los documentos escritos- mucho más que los elementos constitutivos que le dieron origen desde el punto de vista material (KOSSOY, 2001, p. 117)

Además, al realizar esa toma fotográfica se genera un registro que remite a una situación que jamás volverá a existir o al menos, no de la misma forma. Esa supuesta "realidad" captada en una fracción de segundo, nunca se repetirá, entonces estará dando lugar a una nueva "realidad".

Como sostiene Kossoy (2001, p. 23):

Segunda vida perenne e inmóvil, preservando la imagen-miniatura de su referente: reflejos de existencias/ocurrencias, conservados congelados por el registro fotográfico. Contenidos que despiertan sentimientos profundos de afecto, odio y nostalgia en algunos; y exclusivamente medios de conocimiento e información para otros que los observan libres de pasiones, estén próximos o apartados del lugar y de la época en que aquellas imágenes tuvieron su origen. Desaparecidos los escenarios, los personajes y los monumentos, a veces sobreviven los documentos.

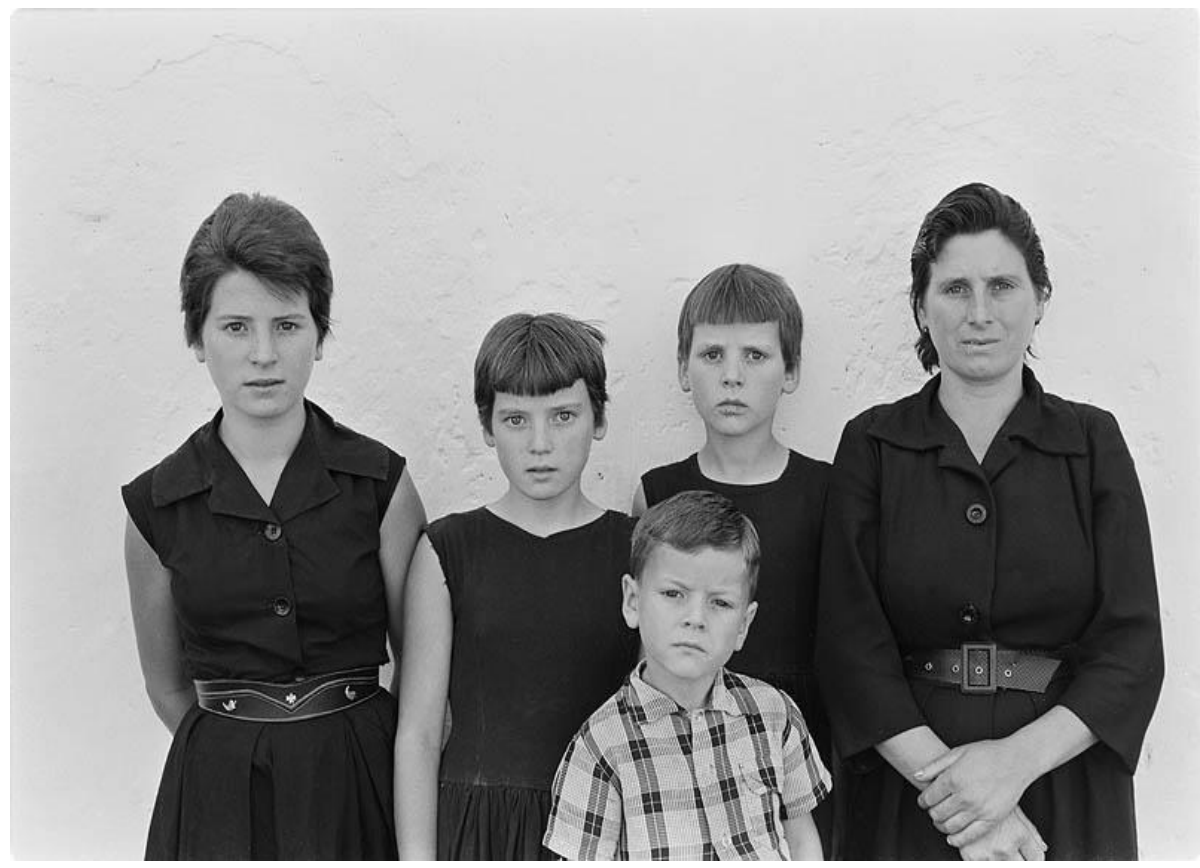

Figura 03. Sin título, 1959-1960

Fonte: Virxilio Vieitez e Vegap (2013) 
¿Y para que las coleccionamos?, ¿Porque la necesidad de resguardarlas?, ¿Cómo dialogan con nuestras colecciones del presente? Las que tenemos hoy y generamos a diario; las de hoy; las colecciones digitales que generamos en las redes sociales ison colecciones individuales o colectivas?

La necesidad de conservar fotografías nace, generalmente, de la identificación emocional hacia alguna imagen fotográfica del pasado, en donde aparece retratado algo que nos conmueve. Muchas veces nos motiva a buscar otras, que ayuden a reconstruir nuestra historia personal. Esta identificación es la misma que tiene la sociedad como un todo hacia su propia historia, la necesidad de rescatar el pasado para mirar hacia atrás, entender y seguir adelante.

Coincidimos con Kossoy (2001, p. 101) cuando sostiene que

...la representación fotográfica refleja y documenta en su contenido no solo una estética inherente a su expresión, sino también una estética de vida ideológicamente preponderante en un determinado contexto social y geográfico, en un momento particular de la historia. Estética e ideología son componentes fluidos e indivisibles, implícitos en la representación fotográfica...

Cuando nos enfrentamos a este tipo de fotografías desde una perspectiva relacionada con la educación artística, las posibilidades de abordaje se multiplican. Si nos posicionamos respecto a los datos que cada imagen contiene, desde el punto de vista de la composición y los contenidos formales, seguramente podremos trabajar en relación a las formas de vida en una época determinada, la vestimenta, las costumbres, los lugares geográficos, etc. Es decir, los elementos que podemos identificar en un primer momento y que forman parte de la selección que realizó quien fotografió ese momento. Esto implicará también poder discutir acerca de esa selección, mirar que nos dice, pero también las ausencias, aquellos elementos que no aparecen en la imagen.

Revista Digital do LAV - Santa Maria - vol. 12, n. 1, p. 95 - 109 - jan./abr. 2019 ISSN 1983 - 7348 http://dx.doi.org/10.5902/1983734837720 


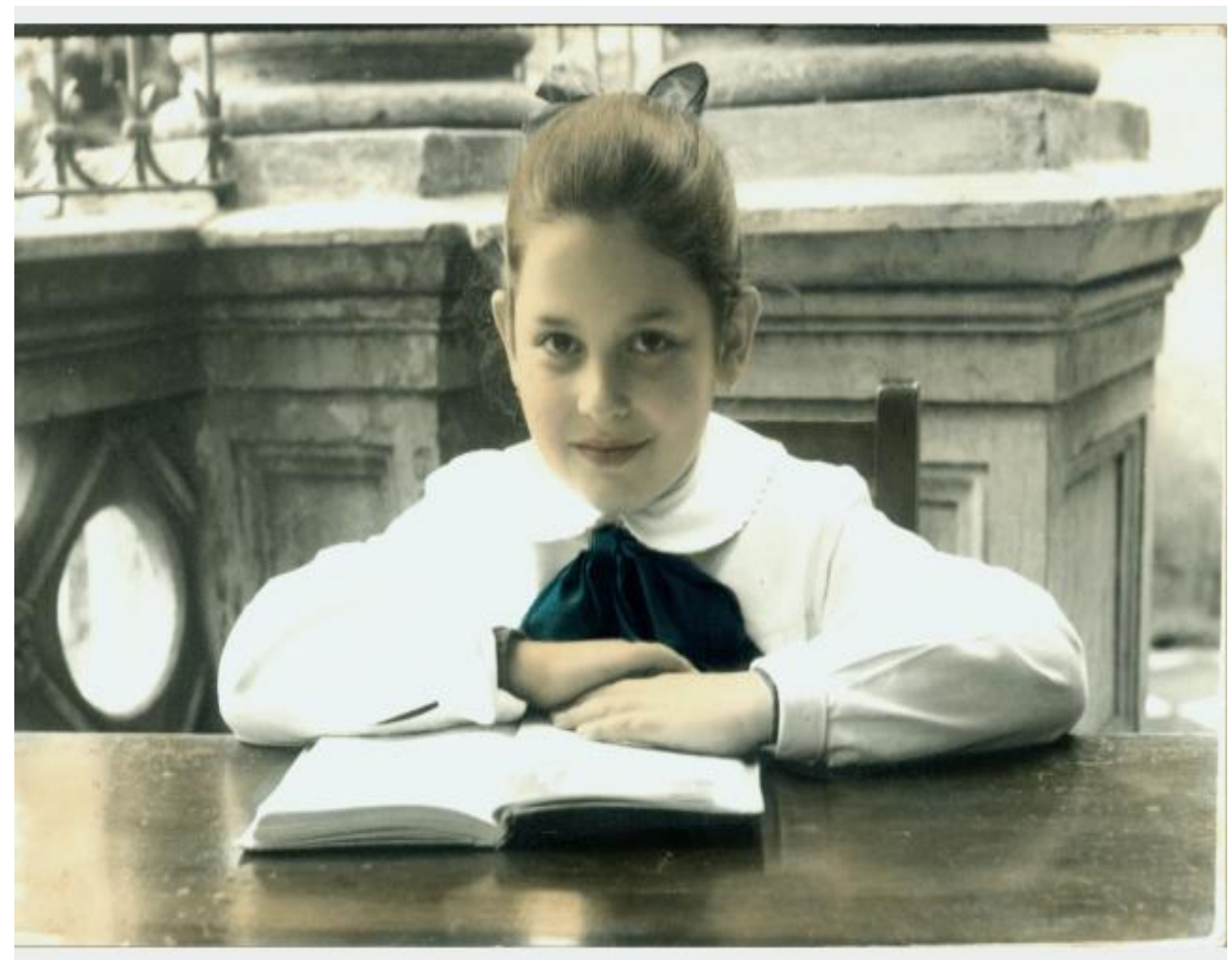

Figura 04. María Emilia Islas Gatti en la Escuela No 79. Año 1965.

Fonte: Proyecto Album de Familia. Centro de Fotografía, Montevideo. ${ }^{2}$

Pero además se construye una arqueología de la imagen si a esos elementos incorporamos una mirada que tome como punto de partida las experiencias de vida de los individuos fotografiados, sus itinerarios, sus contextos históricos, las condiciones en las que se realizó esa fotografía e incluso lo que sucedió con esa persona desde el momento en que se generó esa imagen, seguramente estaremos frente a unas posibilidades de trabajo que trascienden los aspectos técnicos y nos permiten la discusión de diversos enfoques disciplinarios.

\footnotetext{
${ }^{2}$ Album de Familia es un proyecto desarrollado por el Centro de Fotografía de Montevideo, en colaboración con la organización Madres y Familiares de Uruguayos Detenidos Desaparecidos, para la recuperación y organización de fotografías familiares. Ver más información en: http://cdf.montevideo.gub.uy/investigacion/35
}

Revista Digital do LAV - Santa Maria - vol. 12, n. 1, p. 95 - 109 - jan./abr. 2019 ISSN 1983 - 7348 http://dx.doi.org/10.5902/1983734837720 


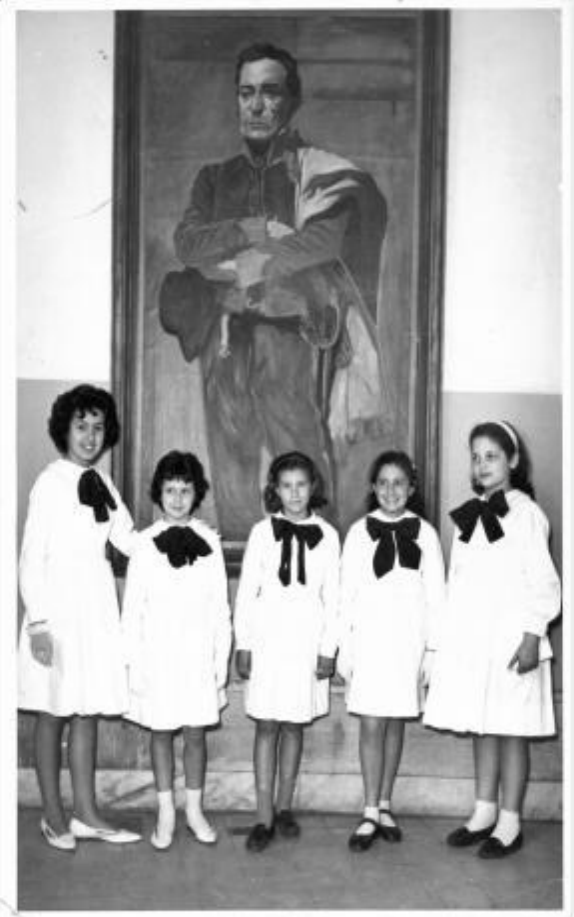

Figura 05. Fin de año escolar de María Emilia en la Escuela Sarmiento.

De izquierda a derecha: Mirta, Cristina, Trinidad, Reyna (compañeras de clase)

$$
\text { y María Emilia. Año } 1969 .
$$

Fonte: Proyecto Album de Familia. Centro de Fotografía, Montevideo.

Como decíamos antes y siguiendo con la idea de archivo o de las imágenes organizadas en colecciones, seleccionadas, deliberadas o aleatorias, es importante pensar que:

El fragmento de la realidad grabado en la fotografía representa el congelamiento del gesto y del paisaje, y por lo tanto la perpetuación de un momento; en otras palabras, de la memoria: memoria del individuo, de la comunidad de las costumbres, del hecho social, del paisaje urbano, de la naturaleza. La escena registrada en la imagen no se repetirá jamás. El momento vivido, congelado por el registro fotográfico, es irreversible. La vida continúa, sin embargo, y la fotografía sigue preservando aquel fragmento congelado de la realidad. Los personajes retratados envejecen y mueren, los escenarios se modifican, se transfiguran y también desaparecen. (...) Si desaparece esa segunda realidad, sea por acto voluntario o involuntario, aquellos personajes mueren por segunda vez. Lo visible fotográfico allí registrado se desmaterializa. Se extinguen el documento y la memoria (KOSSOY, 2001, p. 119).

La recuperación de la memoria histórica o su reconstrucción, ha encontrado en la fotografía una herramienta de mucha importancia para poder re significar discursos y relatos 
construidos desde la mirada historiográfica, De este modo, la fotografía familiar constituye en nuestra contemporaneidad un resguardo de relatos personales, subjetivos, íntimos que dialogan e increpan muchas veces los grandes relatos acerca del devenir de nuestra sociedad. Constituye una fuente inagotable para la micro historia, la historia comparada y la historia de la vida cotidiana.

Las imágenes pueden ser sometidas a análisis estéticos, formales, históricos o a todos ellos, pero sólo las preguntas que cada uno formule posibilitarán conseguir las claves de interpretación buscadas. Burke (2005, p. 12), sostenía que hasta hace unas décadas,

cuando utilizan imágenes, los historiadores suelen tratarlas como simples ilustraciones [...] En los casos en los que las imágenes se analizan en el texto, su testimonio suele utilizarse para ilustrar las conclusiones a las que el autor ya ha llegado por otros medios, y no para dar nuevas respuestas o plantear nuevas cuestiones.

La operación necesaria requiere el cruzamiento de las fotografías con otras fuentes éditas e inéditas y con el recurso de la entrevista; la memoria oral se constituye - en los casos que existan informantes calificados- como fuente de conocimiento sobre ese pasado, no tal como fue, sino como se recuerda y el valor que tuvo para el entrevistado: "Por todo ello, las imágenes constituyen un testimonio del ordenamiento social del pasado y sobre todo de las formas de pensar y de ver las cosas en tiempos pretéritos" (BURKE, 2005, p. 236)

Las colecciones de un acervo se valoran por la calidad de su material, por la información que contienen, por su origen, por el momento histórico, por las condiciones de producción. En el caso del acervo de imágenes, estas proporcionan un repositorio de información que tiene que ver con el contexto donde fueron registradas, pero, además, la visión del mundo que registra: el artista que lo registra, el objeto registrado, y lo que queda fuera del cuadro. La mirada del investigador no puede ser ingenua frente a las fotografías como fuentes; "el historiador no puede permitirse el lujo de olvidar las tendencias contrapuestas que operan en el creador de imágenes, por una parte, a idealizar y por otra a satirizar el mundo que representa" (BURKE, 2005, p. 142).

Indagar acerca de la importancia de la fotografía como documento social, tomando como punto de partida la construcción de imaginarios visuales que se vinculan directamente con la constitución de un proceso histórico determinado, puede ser una posibilidad de abordaje para las fotografías o imágenes que muchas veces coleccionamos.

Revista Digital do LAV - Santa Maria - vol. 12, n. 1, p. 95 - 109 - jan./abr. 2019 ISSN 1983 - 7348 http://dx.doi.org/10.5902/1983734837720 
Pensemos que las imágenes pueden aportarnos una serie de lecturas y miradas desde la premisa de que

A partir del contenido documental que encierran, las fotografías que retratan diferentes aspectos de la vida pasada de un país son importantes para los estudios históricos concernientes a las más diferentes áreas de conocimiento. Esas fuentes fotográficas, tomadas como objeto de un previo examen técnico -iconográfico e interpretativo, se prestan definitivamente para la recuperación de las informaciones (KOSSOY, 2001, p. 44).

Hoy las colecciones fotográficas no tienen un solo formato de archivo, ni un único soporte de conservación y lo que resulta más interesante y desafiante, no se necesita una cámara fotográfica convencional para generarlos.

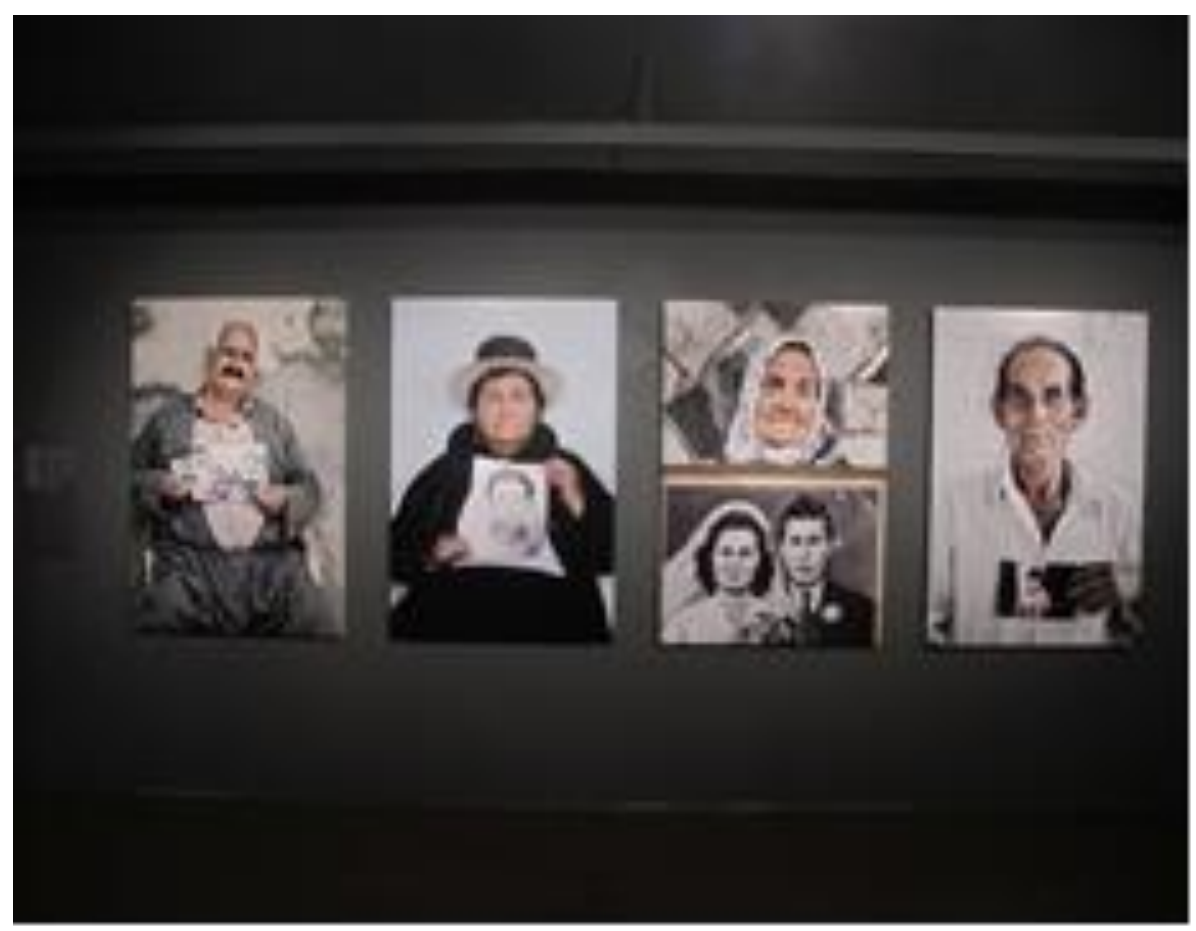

Figura 06. Detalle de la exposición "Desapareguts"

Fonte: (C) CCCB / Jordi Gomez ${ }^{3}$

Hoy tomamos fotografías con nuestros teléfonos móviles o tablets, tenemos un archivo portátil de esas imágenes que llevamos encima de manera permanente y que pocas veces imprimimos en papel, pero podemos subir a la web y de esta forma, las ponemos en diálogo con otros archivos y otros discursos.

\footnotetext{
3 Exposición "Desapareguts" fotografías de Gervasio Sánchez en el Centro de Cultura Contemporánea de Barcelona, 2011. Ver más información en: http://www.cccb.org/es/autor-gervasio_snchez-13021.
}

Revista Digital do LAV - Santa Maria - vol. 12, n. 1, p. 95 - 109 - jan./abr. 2019 ISSN 1983 - 7348 http://dx.doi.org/10.5902/1983734837720 
En este sentido el desarrollo tecnológico genera nuevos escenarios para la producción, circulación y exposición de las imágenes, donde cada individuo tiene la posibilidad de generar sus discursos sin la mediación de un experto, en este caso el fotográfo/artista. Este cambio transforma las prácticas de recepción y desde el campo artístico se habla de la postfotografía, término impulsado por el fotógrafo catalán Joan Fontcuberta, quien sostiene que la fotografía, tal y como la hemos conocido hasta el momento ha muerto y que ahora la fotografía habita en internet, en los dispositivos electrónicos y esta realidad, trastoca y pone en cuestión desde los aspectos formales de la disciplina hasta la condición de autoría, tan discutida en el artes contemporáneo. ${ }^{4}$

En febrero de 2013 se inauguró en el Centro de Arte Santa Mónica de Barcelona, la exposición "From Here On. A partir de Ahora. La postfotografía en la era de Internet y la telefonía móvil". En esta muestra, que está comisariada por Joan Fontcuberta, Joachim Schimd y Erik Kessels, incluía el trabajo de 54 artistas que planteaban un enfoque respecto al estado de la fotografía en el siglo XXI.

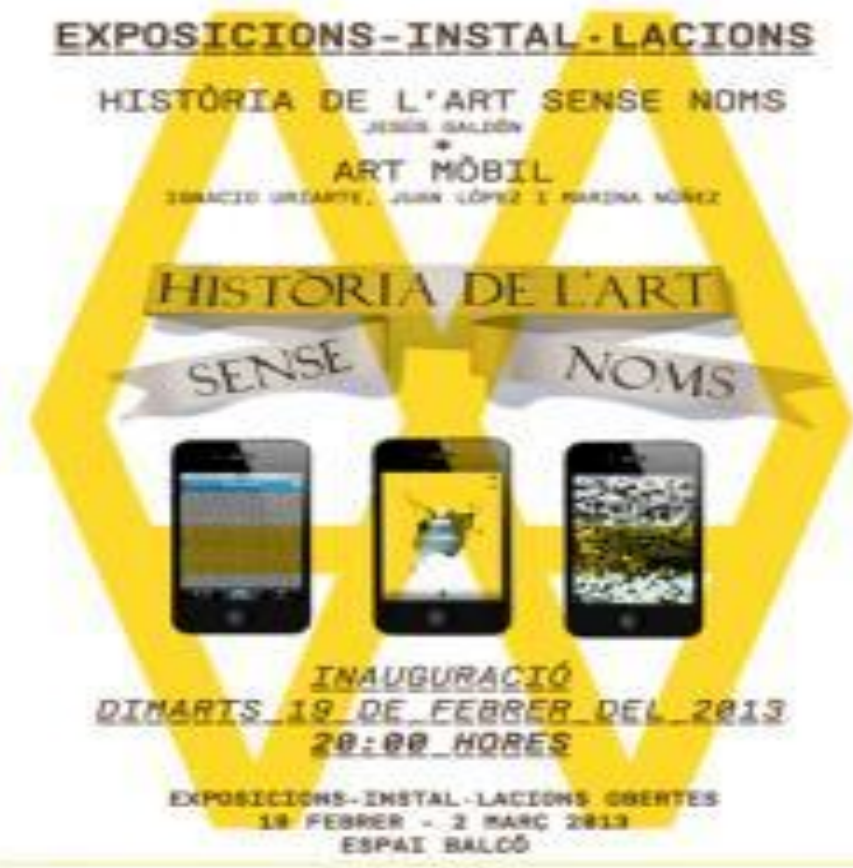

Figura 07. Afiche de la exposición From Here On. A partir de Ahora.

Fonte: La postfotografía en la era de Internet y la telefonía móvil (2013).

\footnotetext{
${ }^{4}$ Fontcuberta, Joan Por un manifiesto posfotográfico. http://www.lavanguardia.com/cultura/20110511/54152218372/por-un-manifiesto-posfotografico.html. Consultado en: 02/02/2013.
}

Revista Digital do LAV - Santa Maria - vol. 12, n. 1, p. 95 - 109 - jan./abr. 2019 ISSN 1983 - 7348 http://dx.doi.org/10.5902/1983734837720 
De alguna manera, ponían en discusión cómo la aceleración en la producción de imágenes y la multiplicidad de soportes desde donde generarlas cuestionan los modos de ver y generar imágenes desde el campo fotográfico.

Discutir los márgenes desde donde cotidianamente generáramos imágenes con nuestros teléfonos celulares, tablets y hasta nuestras búsquedas en internet, como editamos las fotografías, de qué manera perfilamos, construimos y/o modificamos nuestro gusto por tal o cual imagen; son aspectos que necesariamente se ponen en discusión con estos abordajes.

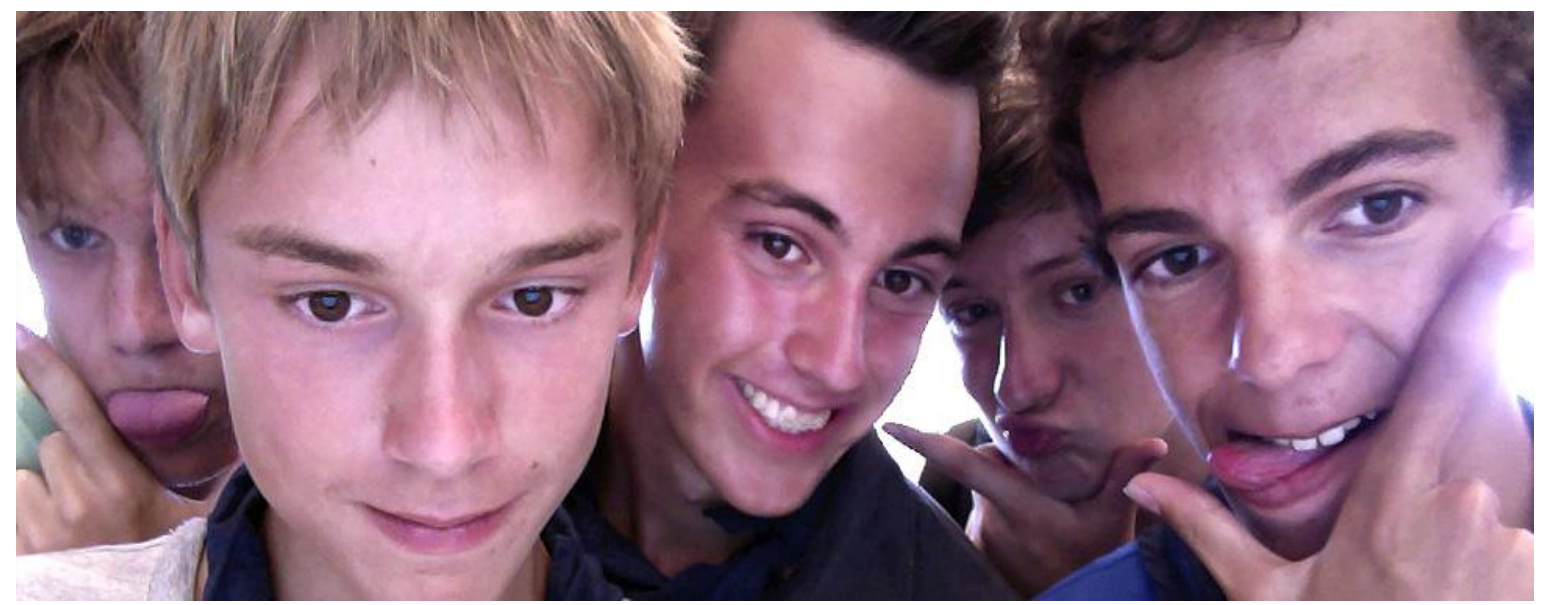

Figura 08. Roc Herms

Fonte: The photobooth recovery. ${ }^{5}$

Al mismo tiempo, como decíamos anteriormente, abordar la reflexión acerca de la fotografía desde los estudios sobre Cultura Visual puede posibilitar otros enfoques que trascienden el específico de la disciplina y se proyectan sobre los mecanismos de construcción de discursos que desde diversos espacios se han generado en relación a la construcción de identidad de cada uno delos individuos.

La cultura visual coloca en nuestros ambientes cotidianos diversidad de imágenes que trasmiten todo tipo de informaciones, discursos, ideologías, noticias, comunicaciones, y que generan emociones y pensamientos en múltiples sentidos; circulaciones inmateriales

\footnotetext{
${ }^{5}$ Ni el nuevo iPad ni el Mac Book Retina. Lo que mas me sorprendió de mi primera visita a la Apple Store de Barcelona, inaugurada el 28 de Julio del 2012, fue la gran cantidad de auto retratos que la gente deja abandonados en el interior de las máquinas que descubrían. Desde entonces visitar la Apple Store ha tomado sentido. Hurgar cajas como en los Encantes, en busca de fotografías antiguas, es de lo mas entretenido. En este álbum se muestran una selección de las imágenes recogidas en el tumblr que sostiene la idea. The Photobooth Recovery pretende ser una colección abierta en la que tu, o cualquier otro peregrino, pueda enviar los diamantes o las setas recogidas.www. thephotoboothrecovery.tumblr.com Roc Herms, 2008: http://www. rocherms.com/album. php?id=1\&idalbum=102\&idioma=Esp\&color=white. Consultado 05/02/2013.
}

Revista Digital do LAV - Santa Maria - vol. 12, n. 1, p. 95 - 109 - jan./abr. 2019 ISSN 1983 - 7348 http://dx.doi.org/10.5902/1983734837720 
de las imágenes donde el aura producida por una expectación con tiempo y espacio se desvanece en la inmediatez y el cambio de ritmo vital.

Pantallas, celulares, plasmas, monitores, y muchas más aplicaciones tecnológicas sustentan la imagen por un momento, el requerido para su visualización. Pero es necesario preguntarnos qué sucede con los acervos de imágenes que se corresponden y sustentan en lógicas modernas de guarda, custodia, exposición y contemplación. Amerita preguntarnos hasta cuándo las guardamos, si las olvidamos o si transformamos su valor desde nuevas acciones creativas.

Es decir, pensar las imágenes que contienen nuestros archivos personales, en formato papel o digital, las fotografías personales y profesionales, puede implicar revisar o volver a ver, las ideas que manejamos respecto a una inmensidad de tópicos que se relacionan directamente con lo cotidiano.

Y lo mismo sucede con los repertorios de fotografías, recopiladas desde un archivo, un centro de documentación, un museo o cualquier institución.

En esas colecciones -en la manera en que están conformadas- se definen cuáles son las condiciones de lo que se preserva, de lo que se guarda, de lo que se muestra, cuales son los discursos a conservar y como dialogan estos con los entrecruzamientos que se producen en la acumulación. De alguna manera, en esas pequeñas batallas por determinar que debe ser recordado y de qué manera, se desarrolla e instaura un modo de uso de la memoria por parte del grupo sociales, que fijan ideas y discursos acerca del valor patrimonial y/o histórico de imágenes, espacios públicos y privados, plazas, monumentos que "determinan" lo que somos y consagran discursos, por lo general interesados y fijos.

La ciudad, el cuerpo, la política, el consumo, la publicidad, los derechos humanos, la historia del arte, la guerra, la inmigración, la violencia, relaciones de género. Son todas éstas imágenes de masculinidad y feminidad; el cuerpo popular y el cuerpo artístico; el trabajo y sus transformaciones; el espacio arquitectónico como generador de heteronomías o autonomías; la moda y una infinidad de temáticas, que las imágenes fotográficas ponen en cuestión a diario. Poder colocar sobre la mesa la diversidad de discursos que circulan en relación a estas temáticas y discutirlos desde una postura crítica en relación a lo que las imágenes nos muestran, puede ser una forma de comenzar a organizar y trabajar en 
relación a la posibilidad de construir nuestras propias imágenes/discursos vinculados a nuestra realidad.

Datos no revelados o mencionados por el lenguaje escrito a través de la historia, toman cuerpo en la imagen fotográfica, incluso sus omisiones o afirmaciones intencionales, así como sus construcciones y discursos en torno a los enfoques de una época determinada.

Diversos fotógrafos se especializan en una temática determinada y desarrollan sus trabajos creando series que perfectamente pueden trabajadas como disparadores para el desarrollo de discusiones en relación a estos temas en espacios relacionados con la educación artística.

\title{
Referencias
}

BARTHES, R. La cámara lúcida. Nota sobre la fotografía. Paidos Buenos Aires, 2009.

BURKE, P. Visto y no visto. El uso de la imagen como documento histórico, Crítica, Barcelona, 2005.

KOSSOY, B. Fotografía e Historia Buenos Aires: la marca, 2001.

SONTAG, S. Sobre la fotografía. Sudamericana, Buenos Aires, 1977.

\begin{abstract}
' Investigador en el Sistema Nacional de Investigadores, Uruguay. Profesor Adjunto del Instituto "Escuela Nacional de Bellas Artes" y Coordinador de la Unidad de Formación y Apoyo Docente del Área Artística de la Universidad de la República. Investigador del Núcleo de Investigación en Cultura Visual, Educación y Construcción de Identidad, del Centro de Investigación, Documentación y Difusión de las Artes Escénicas del Teatro Solís y del Grupo de Pesquisa Cultura Visual e Educação (GPCVE) da Universidade Federal de Goiás. Cursando estudios de Doctorado en Artes y Educación (Universidad de Barcelona) y Licenciado en Artes - Artes Plásticas y Visuales por el Instituto "ENBA" UDELAR.
\end{abstract}

Como citar esse artigo:

GIANOTTI, Gonzalo Vicci. Confluencias entre la educación artística y las tecnologías de la imagen. Revista Digital do LAV, Santa Maria: UFSM, v. 12, n. 1, p. 95-109, jan./abr. 2019.

Revista Digital do LAV - Santa Maria - vol. 12, n. 1, p. 95 - 109 - jan./abr. 2019 ISSN 1983 - 7348 http://dx.doi.org/10.5902/1983734837720 